\title{
Effects of Social and Emotional Learning on Disadvantaged Year 1 Pupils' Understanding of Sinking and Floating Concepts
}

\author{
Ang Sze Wei ${ }^{1}$, Mageswary Karpudewan ${ }^{1 *}$ \\ ${ }^{1}$ School of Educational Studies, Universiti Sains Malaysia, Penang, MALAYSIA
}

Received 30 September 2017 - Revised 21 February 2018 - Accepted 26 March 2018

\begin{abstract}
The purpose of this qualitative case study was to explore Year 1 pupils' understanding about sinking and floating after learning using Social and Emotional Learning (SEL) strategies. A total of 16 Year 1 pupils of low socio-economic background from one class in a rural school participated in this study. The participants were from disadvantaged rural communities; single parents and two pupils were identified with medical problems (thalassemia and mild autism). In this study, three lessons on sinking and floating were imparted using SEL strategies. Data from three sources; worksheets, interviews and observations were triangulated to cross validate the data and to capture richer information to answer the research question. The triangulation of the findings indicates that SEL strategies created a conducive learning environment; reduced disruptive behaviors among the pupils; encouraged engagement and participation in learning. In sum SEL strategies employed to teach sinking and floating resulted in the pupils having a better understanding of these concepts. The research findings imply that ability in managing social and emotional tendency improved their competency particularly in learning abstract science concepts such as sinking and floating.
\end{abstract}

Keywords: disadvantaged pupils, sinking and floating, social and emotional learning, rural school, year 1 pupils

\section{INTRODUCTION}

Social and Emotional Learning (SEL) is rapidly gaining the attention of many educators world-wide (Durlak, Weissberg, Dymnicki, Taylor, \& Schellinger, 2011). Three reviews involving 371 students revealed that SEL produced various benefits including improved academic achievements across kindergarten to grade eight students (Payton et al., 2008). For the purpose of this study, a set of teaching strategies based on SEL principles aimed at establishing a positive relationship among the learning communities, and establishing an encouraging learning environment with reduced challenging behaviors were designed. These teaching strategies were employed to teach sinking and floating concepts to the Year 1 students from disadvantaged rural communities. In this qualitative study, how students developed their understanding of sinking and floating will be reported.

\section{THEORETICAL BACKGROUND}

\section{Social and Emotional Learning (SEL)}

In the classroom context, an individual's thinking is developed during the social interaction between students and the teacher and between peers (Vygostky, 1978). Lessons based on social constructivist perspectives designed using mobile devices have supported students' learning (Krajcik \& Delen, 2017). An inquiry-based socioconstructivist model of shadow formation implemented in a French context involving pre-schoolers contributed to the children's understanding of shadow formation (Impedovo, Delserieys-Pedregosa, Jegou \& Ravanis, 2017). STEM education implemented in many countries using various approaches shown to support students' learning (Tippett \& Milford, 2017). Social interaction is one of the imperative dimensions of STEM education. Findings of

(C) 2018 by the authors; licensee Modestum Ltd., UK. This article is an open access article distributed under the terms and conditions of the Creative Commons Attribution License (http://creativecommons.org/licenses/by/4.0/).

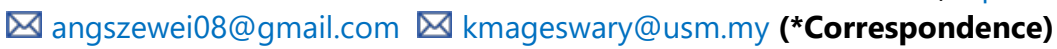




\section{Contribution of this paper to the literature}

- This study exhibits one of the initial examples on the introduction of Social and Emotional Learning approach in teaching science concepts among less disadvantaged Year 1 pupils.

- Up to this end, there is no study, particularly reported on the effectiveness of Social and Emotional Learning Approach in learning science concepts. As such the findings of the study bridge this gap.

- This study suggests how less disadvantaged students able to learn difficult science concepts when they manage to take control of their behaviors and emotions.

- The findings of this study also suggest that the ordinary teaching strategies used in a normal classroom are not appropriate to teach less privileged students with behavioral problems.

these studies elaborated that the interactions during the lessons emotionally supported involvement and engagement of the students in the lessons. The findings from a neuroscience study suggested that there is a direct link between emotions and learning. This is because the emotional centers of the brain are intricately interwoven with the neocortical areas involved in cognitive learning. Fleer (2013) investigated the influences of the affective components (the emotional aspects) on science learning in early years and a study by Tomas and Ritchie (2012) confirmed Fleer's findings and reported that Year 12 students' positive emotions encouraged learning about socioscientific issues.

A study reported academic performance of students increased up to 11 to 17 percentile points with the implementation of SEL programs. SEL programs also showed a significant effect on Chilean $3^{\text {rd }}$ and $4^{\text {th }}$ graders' academic success (Berger, Alcalay, Torretti \& Milicic, 2011). Remarkable improvement in understanding of maths and reading among the low-income kindergarten students and first graders following teaching using SEL programs was explained using the classroom emotional support obtained from the intervention (McCormick, Cappella, O'Connor \& McClowry, 2015).

The above literature indicates that when the students were taught on how to manage their feelings and emotion, results in better control of their behaviors particularly the behaviors expressed in the social context such as in classroom learning. Having better control of the behaviors is particularly important for learning abstract science concepts (i.e., sinking and floating). In contemporary various $S E L$ programs have been implemented and students' overall academic performance was measured. More specific studies were conducted in maths and reading. However, to the best of our knowledge, there is no study that has reported on the influence of SEL programs on an understanding of abstract science concepts at an early stage of schooling, especially involving students from the rural school with low socioeconomic backgrounds. For the purpose of this study, SEL strategies were used to teach sinking and floating concepts to Year 1 students. These students were from a rural and low performing school of low socioeconomic background. By the introduction of SEL strategies, Year 1 students' understanding of sinking and floating was explored.

SEL is a process in which students work collaboratively building skills, values and attitude and ability to manage their emotions better to understand each other in the group. These developments enable students to adapt to complex demands of schooling and learning and to successfully manage their learning (Zins \& Elias, 2007). Particularly, for elementary school children living in disadvantaged urban communities the ability to manage emotions and understand others have an impact on their academic achievement as these competencies are the foundation for the students to perform at an optimum level (Schonfeld et al., 2015). Schonfeld et al. (2015) further listed three main reasons for SEL interventions being effective in improving academic outcomes. These include $S E L$ interventions that teach children to solve problems (identify problems, set goals, generate solutions and evaluate the outcomes), encourage student-teacher relationships in which more opportunity is provided to interact in the classroom and engage in the learning, and with the SEL intervention the classroom will be better managed with less destructive behaviors that enable teachers to deliver complete and effective instructions.

Based on the reasons above various SEL interventions have successfully resulted in improved learning outcomes. For example, Providing Alternative Thinking Strategies (PATHS) is a SEL program for elementary students from kindergarten to grade six employed to bridge the cognitive, academic and socio-emotional development using a set curriculum (Fishbein et al., 2016). Increased emotional awareness, being more socially competent, improved behavior adjustment including reducing destructive behaviors that are derived from the implementation of PATHS collectively explain the program's efficiency in improving academic achievement (Greenberg \& Kusche, 1998). Lessons include instructions that permit children in identifying, labeling, assessing and managing feelings, controlling impulse and reducing stress, using steps for problem-solving and decision making and having nonverbal and verbal communication skills (Goleman, 1995). These lessons were performed using dialoguing, roleplaying, story-telling and modeling (Kelly, Longbottom, Potts \& Williamson, 2004). Improved academic achievement in the PATHS classroom could be explained using the affect-behavior-cognitive-dynamic $(A B C D)$ model on which the PATHS curriculum was based (Greenberg \& Kusche, 1998). The model works on the premise 
that children's emotional development occurs first prior to the behavioral and cognition aspects (Kam, Greenberg \& Kusche, 2004). Emotion developed during the maturation stage is verbalized in the form of behavior and cognition at later stages. Major development of cognitive processing skills occurs between the ages 5 to 10 years. During this phase developmental integrations among affect, behavior and cognition influences the social and emotional formation and ultimately academic achievement (Honess \& Hunter, 2014).

Another example of the SEL approach is called the Responsive Classroom (RC). $R C$ is an approach that focuses on promoting both social and academic learning (Rimm-Kaufman \& McTigue, 2011). Similar to other SEL interventions, $R C$ is also based on the principle of developing positive relationships in the classroom and using appropriate approaches to cultivate learning. Implementation of $R C$ during third, fourth and fifth grades reported improving academic performance (Brock, Nishida, Chiong, Grimm, \& Rimm-Kaufman, 2008). Specifically, RC improved both reading (Koslin, Koslin, Zeno, \& Ivens, 1989) and maths. The improved reading skills and improvement in maths resulted from the positive classroom learning environment created by $R C$ and the activities used. For instance, morning meetings allowed the classroom to be better managed. The practice of greeting every student by name allowed the students to communicate and share in low-stress settings; the group activity encouraged active participation and build class identity and morning messages delivered by the teacher provided a transition to the academic context and aroused interest for the learning.

Studies have found that it is common for children to exhibit behavioral problems and the problems are exacerbated among children from low-income families and children with disabilities (Qi \& Kaiser, 2003). A multitiered intervention model "Teaching Pyramid" was implemented with the intention to educate the pre-schoolers to identify and manage their problems (Fox, Dunlap, Hemmeter, Joseph \& Strain, 2003). The model had reported supporting preschools' development of social-emotional competence, reduced challenging behavioral problems and improved their learning (Hemmeter, Ostrosky \& Fox, 2006). Similar to RC and PATHS, the Teaching Pyramid model is also fundamentally based on the principle establishing positive relationships among the children and providing an environment that encourages learning with fewer behavioral problems. With positive social skills, it is expected that the children will be able to manage their emotions and better understand others. This ultimately will result in the effective execution of any program (Hemmeter et al., 2006).

\section{Sinking and Floating}

Sinking and floating are one of the most broadly studied topics in lower primary education (Kallery, 2015). Concepts associated with sinking and floating are the density of materials, buoyancy, water displacement and Archimedes' Principle. Understanding about density is required to understand the concept of buoyancy. Studies have revealed that the concept of buoyancy and density are too difficult for young pupils to comprehend (Kallery, 2015). In another study, Lehrer et al. (2001) found that young pupils failed to differentiate between weight and density. Some studies (e.g., Butts, Hofman, \& Anderson, 1993) reported that young pupils' explanations about sinking and floating often focus on a single dimension and relate an object's sinking or floating to its size or its weight. Due to these reasons, pupils in most classrooms were found to hold alternative conceptions of floating (Biddulph \& Osborne, 1984). Hsin and Wu (2011) suggested that the use of 'material kind,' rather than introducing the definition of density would be more helpful for the student to understand. This is because in relating the object to the material, pupils would be able to reason and explain the phenomena better (Hardy, Jonen, Möller, \& Stern, 2006).

Havu-Nuutinen (2005) conducted a study to observe the process of conceptual change of pupils about sinking and floating. The study employed inquiry and collaborative learning to help pre-kindergarten to second-grade students to develop the concepts of sinking and floating. A study reported that all children were able to explain the objects' behavior in water by relating to the properties of the objects in the post-interviews. This showed that social interaction and knowledge was collaboratively constructed during the inquiry and collaborative learning processes.

More recently, Hsin and Wu (2011) carried out a study to examine young children's explanations about sinking and floating. The findings suggested that manipulative experiences alone might not be enough for children to further their understandings about objects' behavior in water. This same study revealed that with the aid of scaffolding the teaching, children could better understand about sinking and floating. Kallery (2015) carried out action research to help preschoolers to adjust their initial explanations of objects' behavior in water (sinking or floating) by shifting their attention from the objects to the materials used to make the objects. This study also reported that pupils' knowledge of sinking and floating could be constructed through the adult and child working together on particular learning tasks under adult guidance or in collaboration with more capable peers. In the context where this study has taken place, a minimum collaboration between students; students and teacher emerged. As these students were from a disadvantaged background, they tend to carry their problems from home to the classroom and exhibits various destructive behaviors. Past studies depicted that students from this kind of background should be taught to manage their social and emotional competency. With managing both 
Table 1. Description of participants' characteristics

\begin{tabular}{|c|c|c|}
\hline Pupils & Names & Description of the characteristics of the pupils \\
\hline Pupil 1-4 & $\begin{array}{l}\text { Ellen, Katherine, } \\
\text { Hubert and Wilson }\end{array}$ & These are the smart pupils. They obtained good grades in science. \\
\hline Pupils 5-7 & $\begin{array}{l}\text { May, Jackson and } \\
\text { Sean }\end{array}$ & $\begin{array}{l}\text { These are the average pupils. Jackson and Sean are more proactive than May. They are } \\
\text { willing to participate in class activities, but they are talkative and less attentive in class. }\end{array}$ \\
\hline Pupils 8 and 9 & Queenie and Wendy & $\begin{array}{l}\text { These are passive pupils. Their academic performance is below average. Most of the time, } \\
\text { they just sat quietly and were reluctant to take part in any classroom activity. They are } \\
\text { quiet and less attentive in the class. }\end{array}$ \\
\hline Pupil 10 & Jack & $\begin{array}{l}\text { He as an extrovert pupil. He is good in sports but does not like classroom learning. His } \\
\text { attention is always distracted during class. Most of the time he cannot follow the } \\
\text { instructions in the class. He always disturbs others and does not hand in the homework } \\
\text { given by his teachers. His academic performance indicates that he is weak in his studies. }\end{array}$ \\
\hline Pupil 11 & Zane & $\begin{array}{l}\text { Zane is a pupil with mild autism. Most of the time, he cannot get along with other } \\
\text { classmates well and is unable to control his emotions. He always cries and throws things } \\
\text { when he is angry. }\end{array}$ \\
\hline Pupil 12 & Sunny & $\begin{array}{l}\text { Sunny is a passive and quiet pupil. He is a Thalassemia patient. He is always passive and } \\
\text { reluctant to participate in discussions. He is always seen to be less energetic, sleeps in the } \\
\text { class, faces difficulty to concentrate and has poor stress tolerance. }\end{array}$ \\
\hline Pupil 13-16 & $\begin{array}{l}\text { Darrel, Andy, Trudy } \\
\text { and Nessa }\end{array}$ & $\begin{array}{l}\text { These are the non-native speakers in the class. Language barriers make them unable to } \\
\text { cope with studies in school. Their academic performance is very low and usually appeared } \\
\text { less confident. }\end{array}$ \\
\hline
\end{tabular}

Note. All the given names are pseudonyms

competencies, behaviors are more controlled. As such in this study, SEL strategies were employed to teach the students the lessons on sinking and floating. This is because sinking and floating forms the basis for the Year 1 science curriculum and students face difficulty in understanding these concepts.

\section{Research Question}

The study was guided by the main research question: How do students develop the basic ideas about sinking and floating when SEL strategies were used?

\section{METHODS}

\section{Research Context}

Since the parents invest a large amount of time on their jobs, they focused less on their children's academic performance. There were also pupils with single parents. These pupils with less encouraging support from the parents coupled with the high demand of the education system which requires them to learn seven academic subjects, most of the time appeared less motivated in school. Particularly, enormous challenges were encountered by teachers in delivering abstract science concepts to pupils who faced various constraints in the home environment as well as in schools (Kallery, 2015). SEL being an approach that effectively improves social and emotional competency (Fishbein et al., 2016) of the pupils is expected to encourage pupils learning of science.

\section{Sample}

The sample for this study consisted of 16 seven-year-old Year 1 pupils. The academic achievements of the participants in this study ranged from excellent to very poor. The proportion of the weak academic achievers in the class was larger than the high achievers. Most of the Year 1 pupils in this study had two to three years of preschool education from a local kindergarten before enrolling into Year 1. In preschool, science is not taught as a formal subject. As such the prior knowledge of the pupils was mainly from their daily experiences. At the local kindergarten, the children were handled entirely by one untrained teacher. Two pupils in this class did not receive preschool education. Sunny did not receive a preschool education due to his health problem while Darrel due to poverty was unable to enroll in preschool. In Table 1 the 16 pupils' names and a brief description of their characteristics are provided. The descriptions provided in Table 1 shows that the 16 students possess a fewer similar and some distinctive characteristics. The non-native speakers, apparently due to language barrier unable to cope with the studies; the good ones seem to be able to follow the lessons well; the average students exhibit behavioral issues; some of them are passive learners and students with medical issues. 
Table 2. Progression of the lessons

Lessons Progression of the lessons
Pupils watched the YouTube video clip "Who Sank the Boat". While watching pupils responded to the question who
sank the boat. The pupils were noticed listening and watching the video attentively.
Pupils were asked to draw a picture to reflect their understanding of the video clip.
Pupils were asked to guess behavior (sink and float) of a candy; test the behavior in water; and how the behavior
changed when the candy is wrapped with air.
Pupils worked in group experimenting the behaviors (sinking or floating) of materials provided by the teacher
Greeting and sharing the feelings of each other.
Watched the video clip on making submarine-1.
The teacher demonstrated on how to transform sinking objects to float.
Pupils worked in a group and investigated on how to use the available materials to float the sinking objects.
Greeting and sharing the feelings of each other.
Watched the video clip on making submarine-2.
The teacher demonstrated on how to transform floating objects to sink.
Pupils worked in group investigated on how to use the available materials to sink the floating objects.

\section{Research Design}

In this qualitative descriptive case study Year 1 pupils' understanding about sinking and floating based on teaching using SEL strategies were explored. In total three lessons were performed in six weeks. In lesson 1 pupils were introduced to sinking and floating concepts. In lesson 2 using the knowledge obtained in lesson 1, they were expected to modify sinking objects to float and conversely in lesson 3 pupils were expected to apply the knowledge from lessons 1 and 2 to modify floating objects to sink. Worksheets were provided after lessons 1 and 3; interviews were conducted after the three lessons and observations were performed throughout all the three lessons. Data obtained from these three methods were triangulated to explain the pupils' understanding about sinking and floating.

\section{SEL Teaching Strategies}

The SEL teaching strategies employed in all the three lessons adapted the suggestions proposed by Schonfeld et al. (2015). The lessons executed by Schonfeld covered four major areas: emotional awareness; self-control; problem-solving skills and developing peer relationships. The four major areas proposed by Schonfeld guided the three lessons implemented in this study.

In lesson 1, pupils were introduced to sinking and floating concepts. This lesson highlighted the importance of understanding emotions and to build a good relationship between friends to maintain a conducive environment for learning. In lessons 2 and 3 the focus was more on identifying the problems exist among them, setting goals to solve the problem and ultimately suggesting solutions to the problems. The progression of each lesson is provided in Table 2. The details of lessons 1, 2 and 3 are illustrated in next following section.

\section{Lessons}

Lesson 1. In the introduction, a YouTube video clip "Who Sank the Boat" by Pamela Allen was shown to the pupils. The video clip is about a cow, a donkey, a sheep, a pig and a little mouse who decided to go for a row. Listening to the story the pupils need to predict who will sink the boat? At first, the cow jumped on to a boat. As the boat was about to sink, the donkey jumped in to balance the weight. The pig as fat as butter then stepped on the side and caused a great flutter; the sheep who loves to knit sat at the side to level the boat so that she could knit, and finally the little mouse got onto the boat. While watching each slide, the teacher prompted the pupils with the question 'Who sank the boat?' Pupils were reminded that they were only given a single chance to guess the answer. While the story was in progress, the pupils were noticed gazing onto the screen and listening attentively. Each time when the teacher asked 'who sank the boat' they tried to discuss with their friends and suggest an answer.

After watching the video, pupils were asked to draw their understanding about sinking and floating on a piece of paper. The teacher repetitively reminded the pupils that “This is not a drawing test, you don't have to draw well" so that the pupils could focus more on presenting their understanding rather than drawing. At the same time, the teacher encouraged the pupils to add explanations to the picture. A class discussion was held after the drawing activity to discuss the drawings. Following this, pupils weighed a candy by using their hand and decided whether 
Worksheet 1

$$
\text { 1. Tick the correct answer on the box given }
$$
according to the object's behaviour in the water.

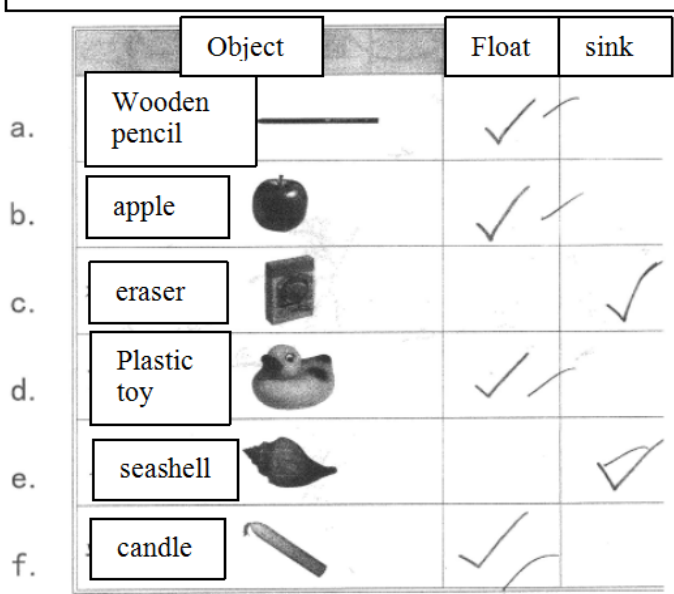

2. Which object float? Which object sink? Fill in the blank with the alphabet which represents the object.

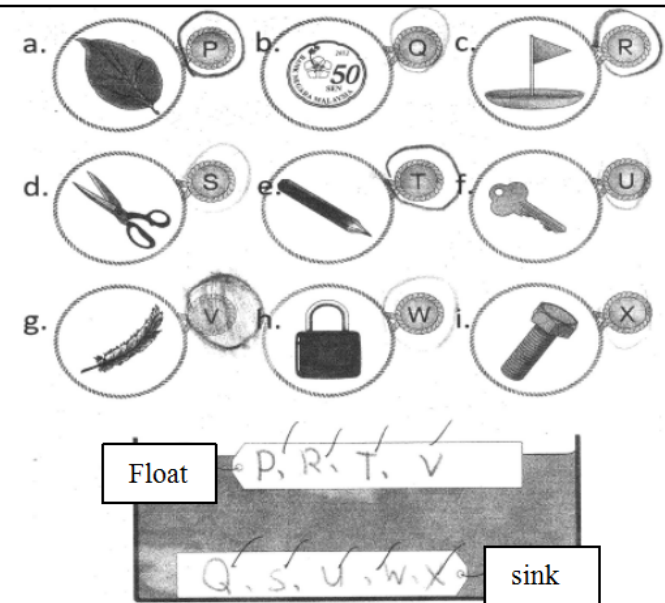

Figure 1. Questions included in Worksheet 1

the candy will float or sink. The candy was put into a transparent container containing water to test its behavior in the water. These steps were repeated by using a milky candy bar with air in the wrapper. This activity encouraged pupils to make predictions and do experiments to prove their prediction.

Then, the pupils carried out experiments to test the behaviors of the objects provided by the teacher in the water. During the activity, the teacher reminded the pupils to follow certain rules in the investigation. Pupils were firstly asked to touch, weigh and observe the objects closely, but not to put the objects into the water until the teacher instructed them to do so. The pupils wrote down their predictions on a piece of paper after observing the objects. After that, the pupils carried out experiments to prove their predictions. The lesson ended with a group discussion lead by the teacher to guide them to generalize their findings. Finally, a worksheet was distributed to assess their understanding of the lesson. Figure 1 illustrates the content of worksheet 1.

Lessons 2 and 3. In lessons 2 and 3, pupils modified sinking objects to float and floating objects to sink followed with presenting their work in front of the class. In both lessons, pupils were given a problem-solving task. They had to solve the problem by following the steps and evaluate their solution and share their feelings after the lesson. The lessons were conducted based on the problem-solving guidelines proposed in the modules (Greenberg \& Kusche, 1998). Both lessons started with the teacher helping calm down the pupils. For this purpose, she asked the pupils to greet each other individually and encouraged them to talk to each other to share their feelings. Some came forward and said that they were not ready to study; unhappy; the day seems to be boring; they are confused about the previous lesson; few said they are not interested with the lesson. If possible, they requested the teacher not to perform the teaching. Upon considering all the pupils' feelings, the teacher diverted the pupils' attention from the stressful to lower stress condition by allowing the pupils to watch a video clip on how to make a submarine available at www.youtube.com/watch? $v=q 15 N y k r D H N 0$. After watching the video, the pupils appeared more cheerful than earlier. After that, the teacher demonstrated how to float a clip. Firstly, she placed a clip into a transparent plastic container with water in it to show that the clip will sink in water. The teacher asked them how they could float the clip. The teacher later tied a cork to the clip using a rubber band and again placed it into the water. It was noticed the clip tied to a cork floats. Following the demonstration, pupils were asked to work in group to float a marble in lesson 2 and to sink a table tennis ball in lesson 3 using the provided materials. In lesson 2, pupils in groups were asked to choose three objects out of ten objects (play dough, clips, candles, rubber bands, wooden blocks of different sizes, sponges, clothes, needles, nails and table tennis balls). Similarly, for lesson 3 they were asked to pick three objects from play dough, clips, sand, rubber band, straws, sponges, marble balls, needles, nails and plastic bags. After many attempts of testing finally, the pupils reached a decision and conclusion. For instance, using the idea from the demonstration, one group tried to float the marble by tying it to a wooden block. They tried to stick the marble to the play dough but failed. Finally, this group managed to float the marble by tying the marble to a bigger wooden block. Another group tried tying the marble to a table tennis ball but again failed to float the marble. At last one student from this group asked permission to cut open the table tennis ball and placed the marble into the tennis ball. With the experience of handling problem-solving tasks in lesson 2, in lesson 3 pupils 


\section{Worksheet 2}

1. Which is the correct way to float the object? Tick on the box given.

a.

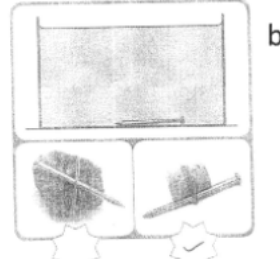

b.

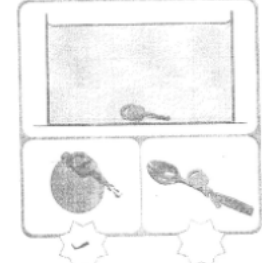

2. Which is the correct way to sink the object? Tick on the box given.

a.
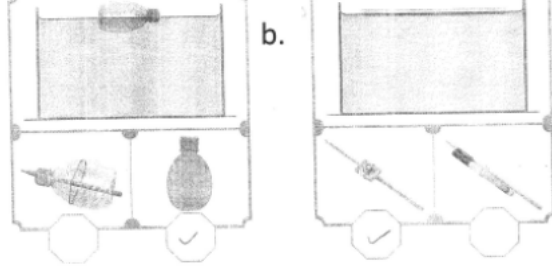

3. Which will float? Which will sink? Circle the correct answer.

a.

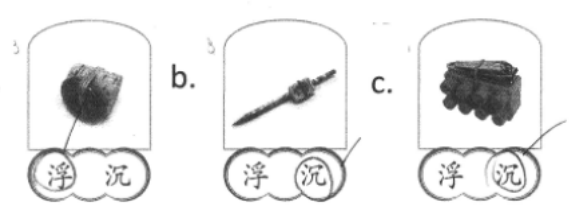

d.

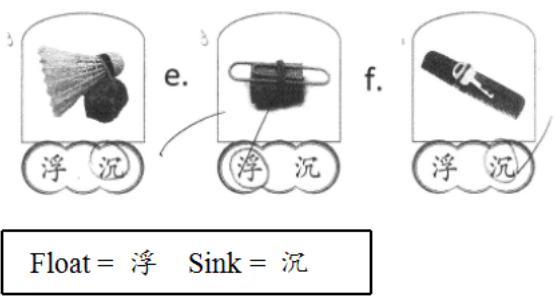

Figure 2. Questions included in Worksheet 2

managed to reach a decision faster when they were asked to sink a table tennis ball. A group of pupils tried to wrap the table tennis ball with play dough but failed to sink the table tennis ball. Finally, the pupils decided to cut open the table tennis ball and filled the inner space of the table tennis ball with play dough. Another group of pupils used a nail to make a hole on the table tennis ball and let the water flow into the table tennis ball to sink it. The other group also made a hole using a nail and filled the table tennis ball with sand and sank it. Worksheet 2 as shown in Figure 2 was used to gauge the understanding obtained from Lesson 2 and 3.

\section{Data Sources}

Floating and sinking worksheets. Pupils were asked to respond to two worksheets. Worksheet 1 was given after lesson 1 and worksheet 2 after lesson 3. The worksheets were adapted from the activity book by Lao and Chiew (2010). In worksheet 1 , pupils needed to determine whether the six objects listed would float or sink. In worksheet 2 three questions were asked: In question 1 a key was placed into a beaker filled with water. Pupils were provided with two options to make the nail float: tie the nail to a bundle of thread or tie an empty tin to the nail. In another beaker, a key was placed into water. Pupils were provided with two options on how to make the key float: tie the spoon to a balloon filled with air or tie the key to a spoon. In question 2 pupils were provided with two situations. In situation 1 , pupils were given a floating empty plastic bottle. They had to decide on how to make the bottle to sink either by tying the bottle to a pencil or filling the bottle with water. In the situation, 2 pupils were provided a pencil floating on the water. In making the pencil of sinking they had to choose between tying the pencil to an eraser or tying the pencil to a marker pencil. In question 3 six situations were given: a coin tied to a cork, a pencil tied to an eraser, a nail clipper tied to a plastic toy, a shuttlecock tied to a stone, a paper clip tied to a cork, a and key tied to a comb. Pupils were asked to decide whether these objects would float or sink when placed in water.

Semi-structured interviews. Semi-structured interviews involving all the 16 participants were conducted after each lesson. The purpose of the interviews was to identify pupils' understanding about sinking and floating and to determine how they applied the knowledge to modify sinking objects to float and vice versa. Following are the interview questions:

(1) Why did some objects float and others sink?

(2) How would you make a nail or a key to float?

(3) How would you make an empty bottle or straw to sink?

During the interviews, questions were added to probe the pupils' understanding further. The probing questions were posed when incorrect, partially correct or no answers were given during the interviews. 
Classroom observations. Observations were conducted throughout all the three lessons. The first author played the role of participant observer and conducted the observations. All the lessons were video-recorded and transcribed to obtain more information. Additionally, field notes were recorded. The first author conducted the observations based on the following: number of pupils who asked questions; the number of questions asked by the pupils and type of questions asked; engagement in learning; participation in group activities; and non-verbal facial expressions.

\section{RESULTS}

\section{Worksheet Analysis}

Analysis of worksheet 1 after lesson 1. After lesson 1, 12 pupils (Wilson, Ellen, Katherine, Hubert, May, Jackson, Sean, Wendy, Zane, Andy, Trudy \& Nessa) were able to correctly identify that a wooden pencil, an apple, a plastic toy, and candle will float on water. An eraser and seashell would sink into the water. On the contrary, three pupils (Queenie, Sunny and Darrel) had indicated that a candle would sink in water. As noticed in the class discussion, these three pupils presumed that the candle was made of plastic. Queenie also had the understanding that an apple would sink in water. These misconceptions might be due to the experiences encountered in their daily lives.

Analysis of worksheet 2 after lessons 2 and 3. Analysis of situation 1 in question 1 of worksheet 2 showed that 13 pupils managed to indicate that the nail that would sink in water but would float when tied to a thread. Only three pupils (Jack, Sunny and Darrel) provided incorrect answers. This showed that Jack, Sunny and Darrel still could not grasp the knowledge learned in lesson 1 firmly. For situation 2 in question 1, all the 16 pupils provided correct answers by saying that a floating key, when tied to a balloon filled with air, would sink. Similarly, for question 2 all the 16 pupils managed to acquire the knowledge that a floating empty plastic bottle would sink when filled with water compared to tying it to a pencil. They also said that a floating pencil would sink when tied to a marker pen rather than to an eraser. For question 3, the majority of the pupils (12) made a correct decision on the characteristic of the objects listed, whether they would float or sink when placed on water. However, four pupils (Darrel, Nessa, Jack and Sunny) made a few incorrect decisions. Darrel and Nessa assumed that the cork which was tied together with a coin would float because the coin which is made of metal is heavy enough to sink the cork. Jack and Sunny assumed that a pencil which was tied together with an eraser would float. According to Sunny, this is due to the size of the pencil which is bigger than the eraser. These kinds of responses indicated that pupils were still having some misconceptions because in deciding sinking or floating pupils only paid attention to a single dimension of the objects (either weight or size) and failed to consider both dimensions as weight and size collectively determine the sinking or floating property of the objects.

\section{Interview Analysis}

Analysis of interview responses after lesson 1. When the question "Why some objects float and others sink?" was asked 12 pupils provided correct responses. Following are the responses provided by the 12 pupils.

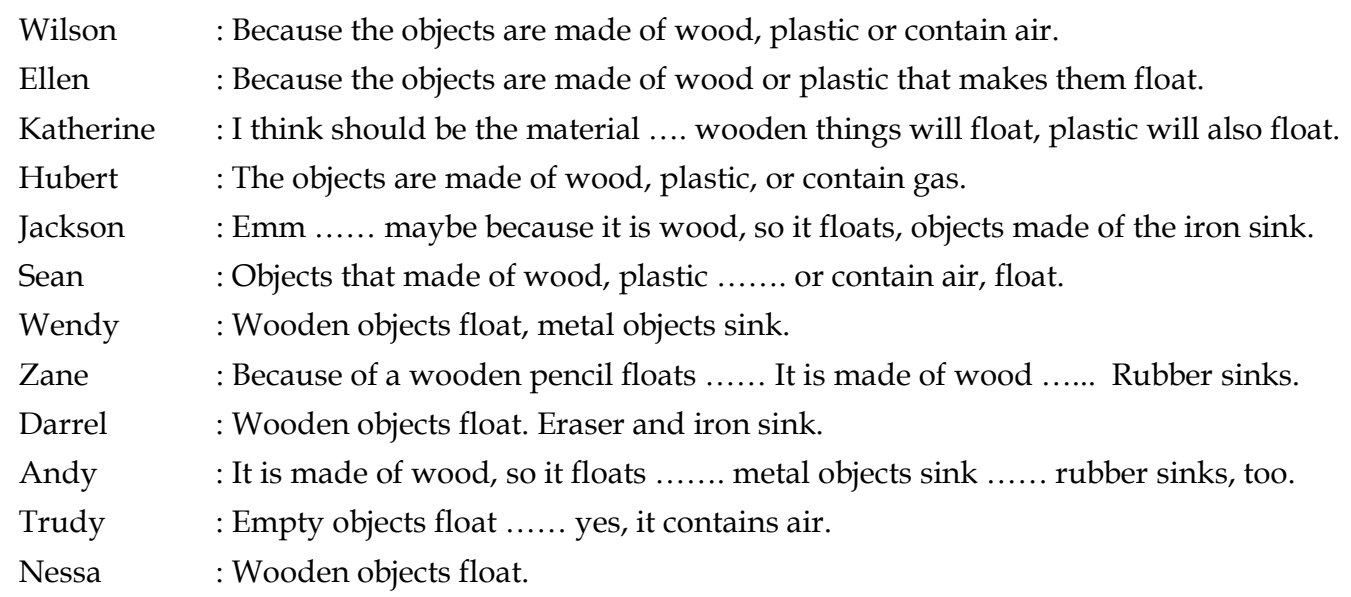

The responses of these 12 pupils indicated that these pupils acquired the knowledge about sinking and floating of an object because of the materials of the objects. The remaining four pupils (May, Queenie, Jack, and Sunny) exhibited partial understanding about the basic ideas of sinking and floating. As shown in the excerpts below initially these pupils mentioned that the weight of the object determined the object's behavior in the water. After 
the interviewer prompted (using questions in italics in the excerpts below), these pupils corrected themselves and were able to provide correct responses as shown below:

May : : Light objects (Are you sure? ..... Do you mean all light objects can float?) .. Oh, No .. Em .. (What kind of objects can float?) the objects that are made of wood.

Queenie $\quad$ : Emm ...... (think back the activity done in the class, Why could some objects float?) because it is light ...... (So you mean that light objects can float?) No .. Em ...... because it is made of wood.

Jack : Because it is light ...... (So you mean that light objects can float?) No, not necessarily light objects float. It also depends on the material. Metal objects sink.

Sunny : Light objects float .. (Are you sure? .. Do you mean all light objects can float?) No, because it is made of wood, so it floats.

Analysis of interview responses for lessons 2 and 3. In order to obtain further insights on how pupils applied their understanding to modify floating objects to sink or vice versa, interviews were conducted. When the question "How would you make a key or a nail float?" was asked, the following are the responses provided by the 16 pupils. The responses obtained were classified into three categories as below:

\section{Pupils who showed firm and excellent understanding}

Katherine, Ellen, Hubert, May, Jackson: Tie the object to another floating object.

\section{Pupils who showed good basic understanding}

Wilson : Put the object on a wooden plank.

Sean : Tie the object to a table tennis ball.

Wendy : Put in a bowl ...... Can it be?

Zane : Put in a bottle ...... empty bottle floats.

Queenie : : Stick it on a ball.

Darrel : Tie together with a table tennis ball.

Andy : Tie together with a table tennis ball.

Trudy : Stick on a wooden block.

Nessa : Tie to a balloon.

Pupils who showed partial understanding

Jack $\quad:$ Em put ... tie to a light object ...... em ...... no ...... stick it to a table tennis ball.

Sunny $\quad$ : Put it on a ship ..... because the ship floats ..... yes ...... tie to floating objects.

From the interview outcomes, it could be postulated that the pupils understood that floating objects could be used to enable sinking objects to float. Katherine, Ellen, Hubert, May and Jackson confidently provided exact correct responses. Other pupils asserted that a nail or key could float if it were tied to a table tennis ball, a balloon or a wooden plank. Wendy appeared less confident with her answer even though she was giving the correct answer. Sunny and Jack showed partial understanding about the lessons. Jack was found to hold some misconceptions about sinking and floating. He assumed that light objects could be used to float a sinking object. When Sunny was prompted by the interviewee to identify ways to make the key or the nail to float guided with the questions: if the key is tied to a rock can the key float? Or if it were tied to a balloon or would the nail float if tied to a tennis ball or cork? He was able to tell that floating objects could be used to make the sinking objects to float after he was prompted by the interviewer.

When the question "How to make an empty bottle or straw to sink?" was asked following are the responses provided by the 16 pupils. The responses were classified into two categories as presented below:

\section{Pupils with firm and excellent understanding}

Ellen : Use a sinking object to help it sink.

Hubert, May, Jackson : Tie it with a sinking object.

Wilson : Put some water or clay in the bottle, make sure there is no air inside, so it cannot float.

\section{Pupils with good basic understanding}

Katherine : Tie the straw with rubber or iron to make it sink.

Sean : Tie it with a magnet bar.

Queenie $\quad:$ Em ...... stick it with an iron rod.

Wendy : Fill the bottle with sand?

Jack : Make a hole in the bottle. 


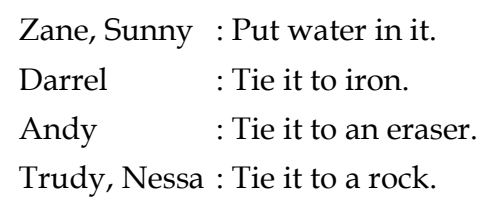

The interview responses indicated that the pupils had a good basic understanding about sinking and floating. The pupils knew sinking objects such as an iron rod, clay and magnet could be used to modify floating objects to sink. It was also noticed that four pupils claimed that tying or sticking the straw or bottle with a sinking object could make the straw or the bottle sink. The interview responses also showed that Wilson could justify his answer very well. This indicated that the pupils were able to apply the knowledge about sinking and floating to modify the floating object to sink excellently.

\section{Classroom Observations (Lessons 1, 2 and 3)}

In lesson 1, it was noticed that none of the pupils asked any questions. In lessons 2 and 3 many questions were asked. In lesson 2 it was noticed that six pupils posed questions to the teacher. This indicated that the interactions between the teacher and the pupils had improved since the first lesson. Questions posed in lesson 2 could be described as questions to clarify the problem-solving tasks and questions of higher order thinking level.

Questions to clarify the problem-solving task

$\begin{array}{ll}\text { Ellen } & \text { : Teacher, can I change the objects chosen just now? } \\ \text { Katherine } & : \text { How to tie the marble and the wooden block? } \\ \text { Hubert } & : \text { Teacher, how can I tie the marble and the wooden block? } \\ \text { May } & \text { : Teacher, shall I change the objects? } \\ \text { Jackson } & : \text { What do we need to do now? Can I change the ball with other objects?; Teacher, shall we use } \\ & \text { the all three objects to modify the marble to make it float? }\end{array}$

Questions with higher order thinking level

Wilson : Can I cut the table tennis ball?

Most of the questions asked by the pupils were regarding problem-solving tasks. It was noticed that Jackson asked the most number of questions during the lesson. This might be due to the lack of understanding in solving the problem-solving task. Meanwhile, it was noticed that Wilson could think critically as the question asked reflected that Wilson had a firm basic idea of sinking and floating and Wilson was able to apply the knowledge of sinking and floating to find a solution to float the marble. From the class observations, it was also noticed that the pupils who asked questions to the teacher were the more capable pupils in the group.

Table 3 shows the number of responses given by the pupils to the questions raised by the teacher during the lessons 1, 2 and 3. As presented in Table 2, on average of 6.31 responses were obtained in lesson 1 . In lesson 2 the average increased to 9 and 11.44 in lesson 3. In lesson 1, it was also noticed that Queenie and Sunny were passive and reluctant to participate in the lesson 1 as they answered only one question. Jack, Jane and Darrel were also very passive in the class. They only answered two questions whereas Nessa, Wendy and Trudy answered four, five, and seven questions raised by the teacher, respectively. Sean, May and Wilson showed moderate engagement in the learning. These three pupils answered eight questions raised by the teacher throughout the lesson. It was noticed that Jackson was highly engaged in the learning process and answered 15 questions asked by the teacher even though he was uncertain about the answers. Besides these Ellen, Katherine and Hubert were also highly engaged in the lesson and answered most of the questions asked by the teacher which are 11, 13 and 14 questions, respectively. These pupils appeared very confident in expressing the answers. In terms of participation in the group, it was found that Queenie and Zane were less engaged in the group activity. It was also observed that Queenie and Zane did not contribute to the group discussion. Queenie sat quietly while Zane did not cooperate with other group members but was doing his work. Therefore, other group members had difficulties to work together with Zane. On the other hand, Jack was noticed to disturb other pupils when the group discussion was in progress. From the observations, Jack was found to have difficulties following the teacher's instruction to complete the task. He walked around in the class when his group members did not entertain him. It was also noticed that Sunny's attention was easily distracted. This student did not listen attentively to the teacher or his friends during the first lesson. This might be due to his health problem as he was diagnosed as a Thalassemia patient. Generally, throughout lesson 1, from their facial expressions, pupils looked cheerful for the whole lesson except Sunny whose eyes looked hollow and did not show any facial expressions. 
Table 3. Number of Responses Given by the Pupils during Lesson 1,2 and 3

\begin{tabular}{|c|c|c|c|}
\hline Student & Lesson 1 & Lesson 2 & Lesson 3 \\
\hline Sunny & 1 & 3 & 7 \\
\hline Darrel & 1 & 3 & 8 \\
\hline Jack & 1 & 5 & 7 \\
\hline Trudy & 5 & 7 & 8 \\
\hline Nessa & 4 & 7 & 8 \\
\hline Wendy & 5 & 8 & 12 \\
\hline Andy & 3 & 8 & 12 \\
\hline Queenie & 1 & 8 & 9 \\
\hline Ellen & 11 & 10 & 13 \\
\hline Katherine & 13 & 10 & 15 \\
\hline Sean & 8 & 10 & 12 \\
\hline May & 8 & 10 & 13 \\
\hline Zane & 1 & 12 & 14 \\
\hline Hubert & 14 & 14 & 15 \\
\hline Jackson & 15 & 15 & 15 \\
\hline Wilson & 8 & 15 & 15 \\
\hline Average & 6.31 & 9 & 11.44 \\
\hline
\end{tabular}

In lesson 2, Jackson and Wilson answered the most numbers of questions (15). The number of pupils who answered 15 questions in lesson 3 increased to three pupils (Jackson, Wilson and Hubert). It was noticed that Sunny and Darrel answered the least questions: three questions in lesson 2, followed by Jack who managed to answer five questions during Lesson 2. In lesson 3 Sunny and Jack answered seven questions each and Darrel answered eight questions. Meanwhile, both Trudy and Nessa answered seven questions in lesson 2 and eight questions each in lesson 3 whereas Wendy, Andy and Queenie answered eight questions each during lesson 2. On the other hand, Wendy and Andy answered 12 questions each in the lesson 3. Queenie showed notable increment in the responses given to the teacher during lesson 2; number of responses given by Queenie increased from one question in Lesson 1 to eight questions in lesson 2 and nine questions in lesson 3. It was also noticed that Zane's responses to the teacher increased from two questions to 12 questions in lesson 2 and 14 questions in lesson 3. Similarly, Wilson's responses to the teacher also showed an increment from lesson 1 to lesson 3 . He answered eight questions in Lesson 1 and 15 questions each in the lessons 2 and 3. It was found that Ellen, Katherine, Sean and May answered ten questions each during lesson 2 while Hubert and Jackson answered 14 questions during lesson 2. It was reported that Sean and Wendy answered 12 questions each whereas Ellen and May answered 13 questions each and Zane answered 14 questions in lesson 3.

The group activities designed in the lessons 2 and 3 were problem-solving tasks. The pupils collaboratively discussed in groups to find out the solutions to float the marble in lesson 2 and sink a table tennis ball in lesson 3. At first, the pupils looked confused. It was observed that the more capable members of the group conferred with the teacher and other group members before solving the problem. The teacher let the pupils solve the problems tentatively before giving any guidance. Queenie and Sunny showed increased participation in group discussions. These two pupils started to involve themselves in the group discussions beginning from the second lesson. It was also noticed that Jack did not walk around the class (as he did in lesson 1) but he did not contribute to the discussion and group activities. This indicated that the SEL strategy was able to reduce occurrences of disruptive behavior in the class.

During the lessons, most of the pupils looked serious when the pupils were conducting the problem-solving task except Jack. At the end of the lesson, the pupils looked cheerful as the pupils gained a strong sense of accomplishment in completing the task successfully. From the pupils' facial expressions, the pupils looked brighter when they were on the problem-solving tasks. The pupils even asked for more similar activities in their future science classes. This might be due to the success in solving the tasks enabled the pupils to gain a strong sense of fulfillment which motivated them to learn more.

\section{DISCUSSION AND CONCLUSION}

In response to the main research question of the study (How do students develop the basic ideas about sinking and floating?), the data obtained from the worksheet indicated that 12 out of 16 pupils developed the basic ideas about sinking and floating. They were able to change their initial misconceptions that light objects float and heavy objects sink to correct conceptions that materials of the objects determined the behaviors of the object in the water. The interview responses and classroom observations showed that pupils were well engaged and participated in the learning. From these findings, it could be postulated that enhanced understanding about sinking and floating 
and the encouraging learning environment was derived from the SEL lessons. From the explanations given in the interviews, the findings of this study revealed that the pupils were able to elaborate on the sinking and floating properties of an object by relating to the material used to make the objects. This is similar to the findings reported in previous studies (Kallery, 2015; McDonald, 2012). McDonald (2012) and Kallery (2015) asserted that 'material kind' would be more appropriate to be introduced to the primary pupils than the term 'density.'

The findings of this study indicated that pupils had actively participated in the learning. Active participation was reflected when the pupils eagerly answered the questions in the class and also enjoyed the group activities. This has subsequently created a positive learning atmosphere which had facilitated pupils' learning and promoted their understanding about sinking and floating. Hence, it could be postulated that the improved knowledge observed among the pupils was probably due to the social interaction that occurred between students and the teacher and between students. The findings obtained from this study are parallel with the claim that during the PATHS (a SEL program) lessons $80 \%$ to $96 \%$ is the instruction time where pupils cooperatively engaged in the learning (Bardon, Dona \& Symons, 2008). As a result of this collaborative learning atmosphere, PATHS lessons developed social and emotional learning effectively and subsequently had resulted in better learning (Bardon et al., 2008).

The PATHS lessons have enabled the pupils to interact effectively and this has resulted in a healthy classroom atmosphere (Martinsone \& Damberga, 2016). A healthy classroom environment was noticed in the SEL lessons because the approaches employed in the $S E L$ lessons provided opportunities for pupils to learn from peers, discuss with peers and carry out tasks together with their peers to explore science and have a whole class discussion (Martinsone \& Damberga, 2016). Similarly, storytelling and hands-on activities in this study helped the pupils to identify their own emotions and be more empathetic and cooperative with others in the group activities or collaborative learning. It facilitated the pupils learning as the pupils worked cooperatively and collaboratively.

The positive outcome derived from the SEL strategies used in this study could be explained using the $A B C D$ model (Kusche \& Greenberg, 1994). The lessons on sinking and floating were based on SEL principles of establishing a positive relationship among the learning communities and setting an encouraging learning environment with reduced challenging behaviors that enabled the pupils to understand their feelings and feelings of others better. By understanding the feelings of others, the pupils learned to respect their friends' opinions, and interacted with them positively. This leads to the improvement in the pupils' social and emotional competence. With better social and emotional competence, the pupils managed their own emotions better. With more stable emotions, the pupils communicated more effectively in the group and class discussions. This subsequently reduced the disruptive behavior in the class and helped to engage them better in the learning process. When the pupils were socially and emotionally competent, they handled the relationships with their friends and the teacher better. These subsequently helped them maintain good communication. The problem-solving tasks in lessons 2 and 3 created more opportunities for the pupils to consider all possible factors when making decisions, reaching to an appropriate conclusion by taking into consideration different viewpoints, and taking responsibility for the decisions. This subsequently helped the pupils to improve their critical thinking skills which enabled them to apply the knowledge learned in modifying floating objects to sink and vice versa.

The studies that were conducted by Kallery (2015) also asserted that collaborative learning was effective in developing the concepts of sinking and floating among young children. Also, Kallery (2015) stated that whole class discussions and group discussions would help to develop children' scientific reasoning skills. Hence, SEL strategies in this study which involved many social learning activities such as collaborative learning, problem-solving tasks, and group and class discussions assisted the pupils to reason their decisions effectively and to critically apply their knowledge of sinking and floating to modify sinking objects to float and vice versa.

In the context of this study, the participating pupils were from a rural area with parents of low socioeconomic background. For pupils from disadvantaged groups, schooling is a challenge. The situation is exacerbated with pupils having single parents, autism and being non-native speakers. Ordinary teaching strategies if employed to teach these kinds of pupils perhaps will further add to pupils' stress levels with tendencies for them to show disinterest in learning. Strategies that permit the teacher and the pupils to understand their emotions and challenges and maintain low-stress levels throughout the lessons such as in SEL, helped to create improved learning contexts. However, in this study, the lessons were focused only on learning about sinking and floating. It is suggested that investigating how SEL strategies could be implemented in learning other science concepts and perhaps involving larger groups of pupils from different rural areas in the future. 


\section{REFERENCES}

Bardon, L. A., Dona, D. P., \& Symons, F. J. (2008). Extending class wide social skills interventions to at-risk minority pupils: A preliminary application of randomization tests combined with single-subject design methodology. Behavioral Disorders, 33(3), 141-152. https:/ / doi.org/10.1177/019874290803300302

Berger, C., Alcalay, L., Torretti, A., \& Milicic, N. (2011). Socio-emotional well-being and academic achievement: Evidence from a multilevel approach. Psicologia: Reflexaoe Critica, 24(2), 344-351. https://doi.org/10.1590/S0102-79722011000200016

Biddulph, F., \& Osborne, R. (1984). Pupils' ideas about floating and sinking. Pupils' ideas about floating and sinking. Research in Science Education, 14(1), 114-124. https:/ / doi.org/10.1007/BF02356797

Brock, L. L., Nishida, T. K., Chiong, C., Grimm, K. J., \& Rimm-Kaufman, S. E. (2008). Children's perceptions of the classroom environment and social and academic performance: A longitudinal analysis of the contribution of the Responsive Classroom approach. Journal of School Psychology, 46(2), 129-149. https:/ / doi.org/10.1016/j.jsp.2007.02.004

Butts, D. P., Hofman, H. M., \& Anderson, M. (1993). Is hands-on experience enough? A study of young children's views of sinking and floating objects. Journal of Elementary Science Education, 5(1), 50-64. https:// doi.org/10.1007/BF03170644

Durlak, J. A., Weissberg, R. P., Dymnicki, A. B., Taylor, R. D., \& Schellinger, K. B. (2011). The impact of enhancing pupils' social and emotional learning: A meta-analysis of school-based universal interventions. Child Development, 82(1), 405-432. https:// doi.org/10.1111/j.1467-8624.2010.01564.x

Fishbein, D. H., Domitrovich, C., Williams, J., Gitukui, S., Guthrie, C., Shapiro, D., \& Greenberg, M. (2016). Shortterm intervention effects of the PATHS Curriculum in young low-income children: Capitalizing on plasticity. The Journal of Primary Prevention, 37(6), 493-511. https://doi.org/10.1007/s10935-016-0452-5

Fleer, M. (2013). Affective imagination in science education: Determining the emotional nature of scientific and technological learning of young children. Research in Science Education, 43(5), 2085-2106. https:/ / doi.org/10.1007/s11165-012-9344-8

Fox, L., Dunlap, G., Hemmeter, M. L., Joseph, G. E., \& Strain, P. S. (2003). The teaching Pyramid: A model for supporting social competence and preventing challenging behavior in young children. Young Children, 58(4), 48-52.

Goleman, D. P. (1995). Emotional intelligence: Why it can matter more than IQ for character, health and lifelong achievement. New York: Bantam

Greenberg, M. T., \& Kusche, C. A. (1998). Preventive interventions for school-age deaf children: The PATHS curriculum. Journal of Deaf Studies and Deaf Education, 3, 49-63. Retrieved from http://www.jstor.org/stable/23805415

Hardy, I., Jonen, A., Möller, K., \& Stern, E. (2006). Effects of instructional support within constructivist learning environments for elementary school students' understanding of "floating and sinking". Journal of Educational Psychology, 98(2), 307-326. https:/ / doi.org/10.1037/0022-0663.98.2.307

Havu-Nuutinen, S. (2005). Examining young children's conceptual change process in floating and sinking from a social constructivist perspective. International Journal of Science Education, 27(3), 259-279. https:/ / doi.org/10.1080/0950069042000243736

Hemmeter, M. L., Ostrosky, M., \& Fox, L. (2006). Social and emotional foundations for early learning: A conceptual model for intervention. School Psychology Review, 35(4), 583-601.

Honess, A., \& Hunter, D. (2014). Teacher perspectives on the implementation of the PATHS curriculum. Educational Psychology in Practice, 30(1), 51-62. https:/ / doi.org/10.1080/02667363.2013.869490

Hsin, C. T., \& Wu, H. K. (2011). Using scaffolding strategies to promote young children's scientific understandings of floating and sinking. Journal of Science Education and Technology, 20(5), 656-666. https:/ / doi.org/10.1007/s10956-011-9310-7

Impedovo, M. A., Delserieys-Pedregosa, A., Jégou, C., \& Ravanis, K. (2017). Shadow formation at preschool from a socio-materiality perspective. Research in Science Education, 47(3), 579-601. https:/ / doi.org/10.1007/s11165016-9518-x

Kallery, M. (2015). Science in early year's education: introducing floating and sinking as a property of matter. International Journal of Early Years Education, 23(1), 31-53. https:// doi.org/10.1080/09669760.2014.999646

Kam, C. M., Greenberg, M. T., \& Kusché, C. A. (2004). Sustained effects of the PATHS curriculum on the social and psychological adjustment of children in special education. Journal of Emotional and Behavioral Disorders, 12(2), 66-78. https:/ / doi.org/10.1177/10634266040120020101 
Kelly, B., Longbottom, J., Potts, F., \& Williamson, J. (2004). Applying emotional intelligence: Exploring the promoting alternative thinking strategies curriculum. Educational Psychology in Practice, 20(3), 221-240. https:/ / doi.org/10.1080/0266736042000251808

Koslin, B. L., Koslin, S., Zeno, S., \& Ivens, S. (1989). The Degrees of Reading Power Test: Primary and standard forms. Brewster, NY: Touchstone Applied Science Associates Degree of Reading Power Services.

Krajcik, J., \& Delen, I. (2017). How to support learners in developing usable and lasting knowledge of STEM. International Journal of Education in Mathematics, Science and Technology, 5(1), 21-28. https:/ / doi.org/10.18404/ijemst.16863

Kusché, C. A., \& Greenberg, M. T. (1994). The PATHS curriculum. South Deerfield, MA: Channing-Beta Co.

Lao, P. T., \& Chiew, L. C. (2010). Dunia, Sains dan Teknologi Tahun 1. Kuala Lumpur; Malaya Press Sdn. Bhd.

Lehrer, R., Schauble, L., Strom, D., \& Pligge, M. (2001). Similarity of form and substance: Modeling material kind. Cognition and Instruction: Twenty-five Years of Progress, 39-74.

Martinsone, B., \& Damberga, I. (2016). Qualitative analysis of teachers' written self-reflections after implementation of a social-emotional learning program in Latvia. International Journal of School E Educational Psychology, 111. https:/ / doi.org/10.1080/21683603.2016.1225236

McCormick, M. P., Cappella, E., O'Connor, E. E., \& McClowry, S. G. (2015). Context matters for social-emotional learning: Examining variation in program impact by dimensions of school climate. American Journal of Community Psychology, 56(1-2), 101-119. https:/ / doi.org/10.1080/00368121.2012.671197

McDonald, J. R. (2012). Does It Sink or Float? Science Activities: Classroom Projects and Curriculum Ideas, 49(3), 77-81.

Payton, J., Weissberg, R. P., Durlak, J. A., Dymnicki, A. B., Taylor, R. D., Schellinger, K. B., \& Pachan, M. (2008). The positive impact of social and emotional learning for kindergarten to eighth-grade pupils: Findings from three scientific reviews. Technical Report. Retrieved on June 29, 2017 from http:/ / files.eric.ed.gov/fulltext/ED505370.pdf

Qi, C. H., \& Kaiser, A. P. (2003). Behavior problems of preschool children from low-income families: Review of the literature. Early Childhood Special Education, 23(4), 188-216.

Rimm-Kaufman, S., \& McTigue, E. (2011). The 'Responsive Classroom' approach and its implications for improving reading and writing. Reading and Writing Quarterly, 27(1-2), 5-24.

Schonfeld, D. J., Adams, R. E., Fredstrom, B. K., Weissberg, R. P., Gilman, R., Voyce, C., Tomlin, R., \& SpeeseLinehan, D. (2015). Cluster-randomized trial demonstrating impact on academic achievement of elementary social-emotional learning. School Psychology Quarterly, 30(3), 406-420.

Tippett, C. D., \& Milford, T. M. (2017). Findings from a Pre-Kindergarten classroom: Making the case for STEM in early childhood education. International Journal of Science and Mathematics Education, 1(15), 67-86.

Tomas, L., \& Ritchie, S. M. (2012). Positive emotional responses to hybridised writing about a socio-scientific issue. Research in Science Education, 42(1), 25-49. https:/ / doi.org/10.1007/s11165-011-9255-0

Vygotsky, L. S. (1978). Mind and society: The development of higher mental processes. Cambridge, MA: Harvard University Press.

Zins, J. E., \& Elias, M. J. (2007). Social and emotional learning: Promoting the development of all pupils. Journal of Educational and Psychological Consultation, 17(2-3), 233-255.

\section{http://www.ejmste.com}

